\title{
CEPHALOMETRIC ANALYSIS OF CONDYLAR. ADAPTATIONS TO ALTERED MANDIBULAR POSITION IN ADULT RHESUS MONKEYS, MACACA MULATTA
}

\author{
E. D. SChneiderman and D. S. Carlson \\ Departments of Orthodontics, Anatomy and Cell Biology, Anthropology and Center for Human Growth \\ and Development, The University of Michigan, Ann Arbor, MI 48109, U.S.A.
}

\begin{abstract}
Summary-Morphological adaptation to altered position of the mandible was investigated in 19 young adult rhesus monkeys ( $n=10$ experiment and 9 control). The experimental animals had a bite-splint cemented to the maxillary dentition which opened the bite interincisally by $15 \mathrm{~mm}$ and was worn continuously for 48 weeks. Lateral radiographic cephalograms were taken prior to the experiment and at 12-week intervals thereafter. Computerized cephalometry, facilitated by the use of radio-opaque bone markers, was used to assess changes in mandibular position and morphology. An immediate effect of the hite-splint was the clockwise rotation (opening) of the mandible and anterior translation of the condyle on the articular eminence, much as occurs normally during jaw depression. During the next 48 weeks, the mandible (1) rotated anti-clockwise (closed) due mainly to antero-superior displacement of the maxilla and intrusion of the mandibular dentition and (2) underwent a significant increase in length $(p<0.05)$. These findings indicate that the mandibular condyle of young adult monkeys is capable of small, but biologically significant, compensatory growth after displacement.
\end{abstract}

\section{INTRODUCTION}

Several experimental studies have provided evidence that habitual protrusion of the lower jaw can lead to increased condylar growth in young rats and rhesus monkeys (McNamara, 1972; McNamara and Carlson, 1979; Petrovic, Stutzmann and Gasson, 1981). Many of these studies have concluded that similar condylar adaptations do not occur in adults (McNamara, 1972; Petrovic et al., 1981; Hiniker and Ramfjord, 1966; Meikle, 1970; Ramfjord and Enlow, 1971). However, it is clear that growth-related adaptations do occur in the adult craniofacial skeleton in response to altered orofacial form and function. For example, in an analysis of adaptations after increasing the vertical dimension of the lower face in adult rhesus monkeys, we found significant displacement of the entire maxillary complex, which could only have occurred as a result of marked growth along several of the sutures bounding the maxilla (Carlson and Schneiderman, 1983).

Our present purpose was to analyse mandibular adaptations in the same animals in which maxillary adaptations were found. Increasing the vertical dimension of the lower face through the use of the bite-opening appliance resulted in forward translation of the mandibular condyle as normally takes place during jaw depression. The condyle was maintained in a forward position, much as in experimental studies involving mandibular protrusion ( $\mathrm{McNa}$ mara, 1972; Petrovic et al., 1981; Hiniker and Ramfjord, 1966). Based on previous studies of condylar growth and adaptation in adults, we expected no significant evidence of condylar growth

\section{MATERIALS AND METHODS}

\section{Experimental animals}

Nineteen young adult female monkeys, Macaca mulatta, ten experimental and nine control, were used. The animals ranged in age from 6 to 9 years judging from the presence of complete permanent dentitions (Hurme and Van Wagenen, 1961) and occlusal wear (Gantt, 1979).

\section{Appliance}

An intraoral occlusal appliance made of tantalum was cemented to the maxillary dentitions of each experimental animal (Carlson et al., 1982). The device opened the bite inter-incisally $15.0-18.0 \mathrm{~mm}$, repositioned the body of the mandible posteroinferiorly, caused the mandibular condyle to be translated on to the articular eminence, and stretched the masseter muscle by 10 to 15 per cent (Carlson and Scheiderman, 1983). Despite these changes in the position of the mandible, no animal had difficulty eating the normal diet of monkey chow and fruit or displaying agonistically.

\section{Cephalometric and statistical analysis}

Radio-opaque tantalum implants, approx. $1.5 \mathrm{~mm}$ in length, were placed in the mandibular symphysis, mandibular body and cranial base, as well as in other regions of the skull according to the techniques of Björk (1968), McNamara (1972) and McNamara, Riolo and Enlow (1976) to facilitate precise superimposition of serial lateral cephalograms of the monkeys. Animals were radiographed immediately before (interval A) and after (interval 0) the cementation of the appliance and at 12-week intervals thereafter for 48 weeks. A digitizing tablet connected to The University of Michigan's computing system was employed to enter the coordinate data from tracings of the cephalograms.

The radio-opaque implants were used to define two coordinate systems from which it was possible to describe skeletal changes (Figs 1A and 1B). (1) Trans- 

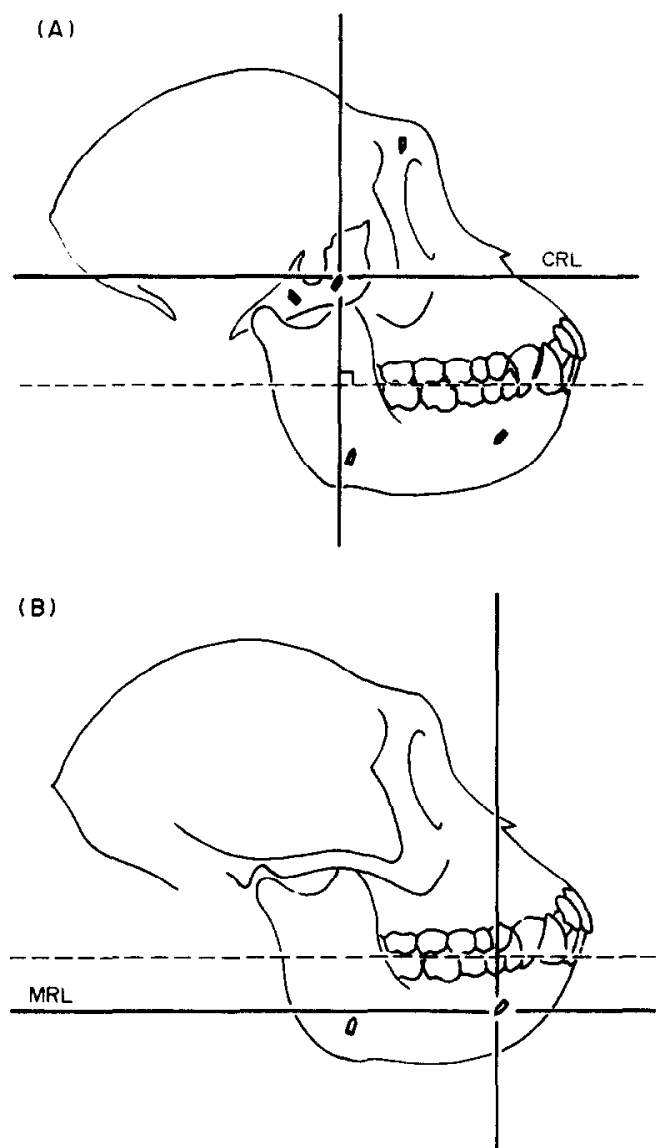

Fig. 1. Conrdinate systems in which measurements were made. (A) CRL system based on the cranial-base implants used for assessing changes in mandibular position. (B) MRL system based on the mandibular implants used to assess remodelling within the mandible.

lation and rotation of the mandible were assessed relative to the cranial-base implants. The cranial reference line (CRL), which originates at the sphenoid-bone marker and is parallel to the original functional occlusal plane, is the abscissa of this coordinate system (Fig. 1A). (2) Remodelling of the mandible was assessed relative to an analogous coordinate system based upon the implants placed in the symphyseal region and body of the mandible. Struc- tural changes within the mandible are expressed relative to the abscissa of the coordinate system, the mandibular reference line (MRL), which originates at the symphyseal bone implant and is also parallel to the original occlusal plane (Fig. 1B).

Examination of histograms and descriptive statistics, including measures of skewness and kurtosis, indicated that all the mandibular variables had approximately normal distributions. Therefore parametric statistics were used to analyse the data. Student's $t$-test was used to compare overall changes between the two groups at the end of the experiment. Additionally, the Behrens-Fisher test was used to evaluate the difference in means when the variances were unequal (Fox and Guire, 1976; Robinson, 1982). Paired $t$-tests were used to determine whether serial changes within groups were significantly different from zero. To minimize the experimentwise error with the multiple paired $t$-tests, Bonferroni corrections were used (Neter and Wasserman, 1974; Alt, 1982).

The third molars had erupted into occlusion at the start of the experiment. Nevertheless, variation in occlusal wear suggested some age variability. Therefore the ages were estimated from the amount of dentine exposure (Gantt, 1979), time of molar eruption prior to the experiment (Hurme and Van Wagenen, 1961), and a few known birth dates. Leastsquares regressions were used to evaluate the effects of age upon the expression of the various adaptations. One-way analysis of covariance was applied to standardize for the effects of age where appropriate.

\section{RESULTS}

\section{Mandibular position (Table l)}

Rotation. The bite-opening appliance produced translation of the condyle on to the articular eminence in conjunction with the clockwise rotation of the entire mandible about the eminence in each of the experimental animals, much as would occur with normal, voluntary jaw opening. By measuring the angle between the MRL and CRL before and after placement of the appliance, it was possible to determine that the mean amount of clockwise rotation produced by the appliance was $12.9^{\circ}$ (Fig. 2). Clockwise is used here in reference to a lateral cephalogram in which the face is oriented towards the right.

Table 1. Changes in mandibular position relative to cranium (A, immediately before, and 0 , immediately after appliance placement)

\begin{tabular}{|c|c|c|c|c|c|}
\hline \multirow{2}{*}{$\begin{array}{l}\text { Experimental } \\
\text { group and } \\
\text { and interval } \\
\text { (weeks) }\end{array}$} & \multicolumn{2}{|c|}{$\begin{array}{l}\text { Symphyseal implant } \\
\text { position }(\mathrm{mm})\end{array}$} & \multirow{2}{*}{$\begin{array}{c}\text { MRL-CRL angle } \\
\text { (degrees) } \\
\text { mean }( \pm \mathrm{SD})\end{array}$} & \multicolumn{2}{|c|}{$\begin{array}{l}\text { Condylar position; } \\
\text { displacement (mm) }\end{array}$} \\
\hline & $\begin{array}{c}\text { Horizontal, } \\
\text { mean }( \pm \mathrm{SD})\end{array}$ & $\begin{array}{c}\text { Vertical, } \\
\text { mean }( \pm S D)\end{array}$ & & $\begin{array}{c}\text { Ilorizontal, } \\
\text { mean }( \pm S D)\end{array}$ & $\begin{array}{c}\text { Vertical, } \\
\text { mean }( \pm S D)\end{array}$ \\
\hline \multicolumn{6}{|l|}{ Control $(N=9)$} \\
\hline & $0.67(0.77)$ & $-0.67(0.96)$ & $0.17(1.95)$ & $-0.04(0.83)$ & $0.76(0.95)$ \\
\hline \multicolumn{6}{|c|}{ Experimental $(N=10)$} \\
\hline $\mathrm{A}-0$ & $-5.91(1.27) \S$ & $-13.75(1.14) \S$ & $12.89(2.12) \S$ & $1.60(0.76) \S$ & -0.02 \\
\hline $0-12$ & $2.43(0.82) \S$ & $3.20(0.76) \S$ & $-3.86(2.62) \S$ & $-0.30(0.66)$ & $0.03(0.73)$ \\
\hline $12-24$ & $1.35(0.83) \S$ & $1.19(0.80) \S$ & $-1.43(1.39) \S$ & $0.08(0.59)$ & $0.08(0.35)$ \\
\hline $24-48$ & $1.43(0.83) \S$ & $0.78(0.37) \S$ & $-1.35(1.16) \S$ & $0.08(0.68)$ & $0.00(0.61)$ \\
\hline $0-48$ & $5.35(1.63) \ddagger \S$ & $5.21(1.30)+\S$ & $-6.58(2.34) \ddagger \S$ & $0.21(0.95)$ & $0.11(1.02)$ \\
\hline$A-48$ & $-2.18(1$ & $-8.49(1.21)^{+} \S$ & $6.68(2.14) \ddagger \S$ & $1.50(1.23)^{*} \S$ & $\S 0.08(0.99)$ \\
\hline
\end{tabular}

Experimental $\neq$ control: ${ }^{*} p<0.05 ; \dagger p<0.005 ; \ddagger p<0.0001$. Value $\neq 0$ : $\$ p<0.05$. 


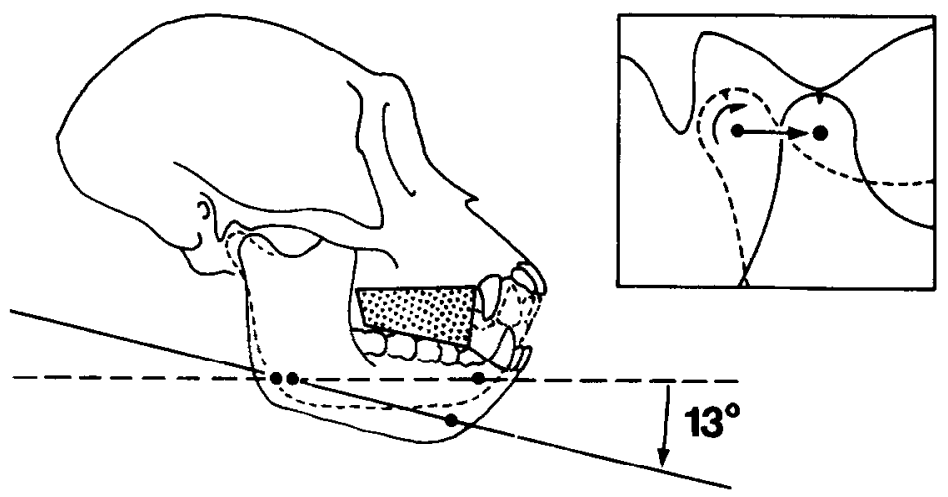

Fig. 2. Immediate effect of appliance: clockwise rotation of the mandible and anterior translation of the condyle (insert).

Over the course of 48 weeks, the mandibles of the experimental animals rotated anti-clockwise an average of $6.6^{\circ}$, resulting in a partial restoration of the original MRL-CRL relationship (Fig. 3). This rotation was brought about by the antero-superior translation of the maxilla and intrusion of the mandibular dentition (Carlson and Schneiderman, 1983). The total extent of anti-clockwise rotation was significantly different from that occurring in the controls $(p<0.0001)$.

By following the position of the symphyseal bone marker relative to the CRL, it was possible to partition mandibular repositioning into vertical and horizontal components. Immediately after the cementation of the appliance the mandibular symphysis was repositioned, on average, $13.8 \mathrm{~mm}$ inferiorly and $5.9 \mathrm{~mm}$ posteriorly in the experimental group. Over the remainder of the experiment, the symphysis moved about $5.2 \mathrm{~mm}$ superiorly and $5.4 \mathrm{~mm}$ anteriorly relative to the CRL.

Condylar displacement. The position of the mandibular condyle in the fossa was determined with the mandibular dentition occluded against the appliance. Changes in the perpendicular distance between superior condylion (the most superior point along the condyle relative to the MRL) and the CRL defined displacement of the condyle from the fossa in the vertical dimension. Horizontal condylar displacement was assessed by measuring change in the position of superior condylion parallel to the CRL.
Student's $t$-test using Bonferroni corrections revealed no significant differences between the experimental and control groups in the vertical position of the condyle at any observation (the Bonferroni corrections require that the individual tests attain significance at the 0.0125 level to preserve the nominal significance level of 0.05 for the experiment). Similarly, paired $t$-tests using Bonferroni corrections showed no significant serial changes within either group in the vertical position of the condyle. On the other hand, there was significant initial anterior displacement of the condyle in the treated animals that persisted throughout the experiment. Over the remainder of the experiment, changes in these dimensions did not differ significantly between groups.

\section{Mandibular growth (Table 2)}

Mandibular length. The change in the distance between the symphyseal implant and condylion (the most postero-superior point on the condyle) was regarded as the most reliable and informative measure of change in the overall length of the mandible. The symphyseal implants were uniformly stable. Changes in this measure are therefore indicative of gain or loss of bone at the condyle (Fig. 4).

Student's $t$-test and the Behrens-Fisher test showed that increases in mandibular length over the course of the 48-week experimental period were markedly greater in the experimental group than in the controls $(p<0.05)$. Whereas the mean length-

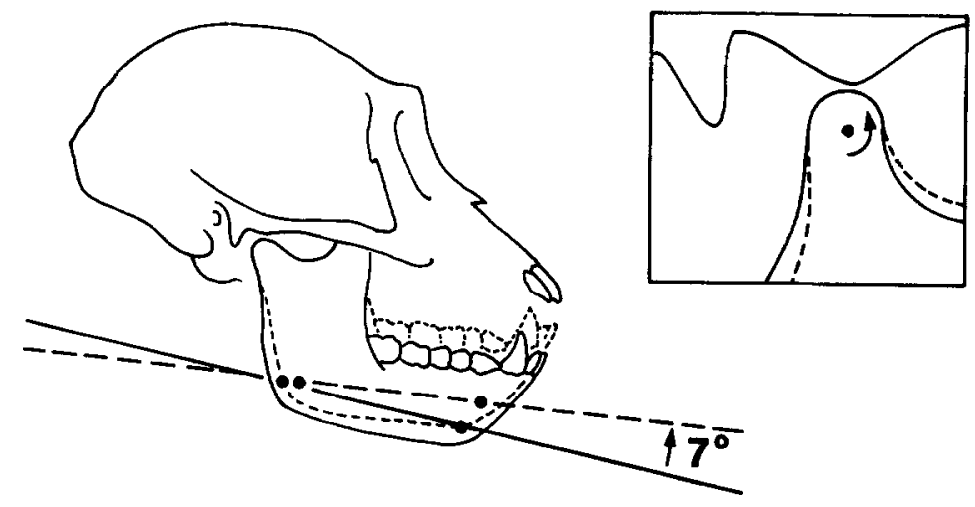

Fig. 3. Change in mandibular position after 48 weeks of treatment with appliance: anti-clockwise rotation. 
Table 2. Changes within the mandible

\begin{tabular}{lcccc}
\hline $\begin{array}{c}\text { Experimental } \\
\text { group and } \\
\text { interval } \\
\text { (weeks) }\end{array}$ & $\begin{array}{c}\text { Length to condylion }(\mathrm{mm}) \\
\text { mean }( \pm \mathrm{SD})\end{array}$ & $\begin{array}{c}\text { Posterior condylion } \\
\text { along MRL }(\mathrm{mm}), \\
\text { mean }( \pm \mathrm{SD})\end{array}$ & $\begin{array}{c}\text { Superior condylior } \\
\text { to MRL }(\mathrm{mm}), \\
\text { mean }( \pm S D)\end{array}$ & $\begin{array}{c}\text { Gonial angle } \\
\text { (degrees), } \\
\text { mean }( \pm \mathrm{SD})\end{array}$ \\
\hline $\begin{array}{c}\text { Control }(N=9) \\
\text { A-48 }\end{array}$ & $0.32(0.41)$ & $0.41(0.57)$ & $0.21(1.82)$ & $-0.37(1.06)$ \\
$\begin{array}{c}\text { Experimental }(N=0) \\
\text { A-0 }\end{array}$ & $0.17(0.28)$ & $-0.02(0.45)$ & $-0.18(0.48)$ & $0.27(1.51)$ \\
$0-12$ & $0.23(0.67)$ & $1.16(1.09)$ & $1.03(2.20)$ & $1.49(2.28)$ \\
$12-24$ & $0.11(0.80)$ & $0.15(1.11)$ & $-0.19(1.69)$ & $-0.20(1.34)$ \\
$24-48$ & $0.76(0.74)^{*}$ & $0.76(0.75)$ & $-0.41(0.76)$ & $0.81(1.80)$ \\
A-48 & $1.46(1.09)^{* \dagger}$ & $1.55(1.25)^{* \dagger}$ & $0.12(1.58)$ & $2.13(2.30)^{* \dagger}$ \\
\hline
\end{tabular}

Experimental $\neq$ control: ${ }^{*} p<0.05$. Value $\neq 0: \dagger p<0.05$.

ening of $1.46 \mathrm{~mm}$ observed in the experimental group was highly significantly different from zero $(p<0.005)$, the $0.32 \mathrm{~mm}$ increment in the controls was not significant $(p=0.06)$. After the effects of age were removed by the analysis of covariance, the adjusted values became more disparate $(p<0.005)$. Also of interest was the finding that the variance for change in mandibular length was significantly higher in the experimental group $(p<0.05)$.

Condylar adaptations. Measurements to superior and posterior condylion were taken to provide specific information on condylar remodelling. To determine changes at superior condylion, perpendicular distances between this point and the MRL were measured. Changes at posterior condylion were determined by projecting this point down to the MRL and measuring the changes along this line.

Consistent with the changes found in mandibular length, mean increments at posterior condylion in the experimental animals were about three times greater than in the controls $(p<0.05)$. The effects of age upon changes at posterior condylion were not significant. The changes occurring over 48 weeks at superior condylion did not parallel changes at condylion or posterior condylion. The mean values of less than $0.30 \mathrm{~mm}$ for each group did not differ significantly from each other or from zero.

These data indicate that the condyle was growing mainly in a postero-superior rather than a superior direction under both control and experimental conditions. However, the magnitude of growth observed in the experimental monkeys was significantly greater than in the controls. This is supported further by the finding that the gonial angle increased $2.0^{\circ}$ in the

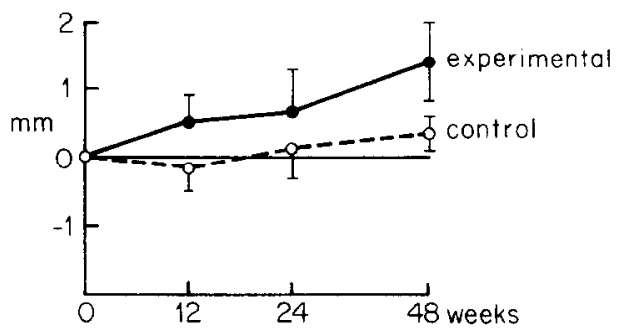

Fig. 4. Means and 95 per cent confidence intervals for changes in mandibular length, as measured from the symphyseal implant to condylion. experimental animals, and decreased $0.4^{\circ}$ in the controls over the course of the experiment $(p<0.05)$. Superimposition of the mandible on the mandibular implants demonstrated that this change in gonial angle is indicative of addition of bone along the upper part of the posterior border of the ramus.

\section{Qualitative observations}

Scrutiny of superimpositions of the tracings and radiographs yielded the following observations in the experimental animals.

(1) In addition to the gain of bone along the posterior and postero-superior aspects of the condyle, there was deposition of bone along the contiguous surface of the posterior margin of the condylar neck.

(2) There were no changes along the mental or inferior margins of the mandible.

(3) As part of the anti-clockwise rotation of the mandible as a whole, condylion rotated away from the articular eminence. This served to place superior condylion in close proximity to the articular eminence.

\section{DISCUSSION}

Positional as well as structural changes occur in the musculoskeletal complex in response to altered mandibular position. The introduction of the biteopening appliance initially rotated the mandibular corpus in a clockwise direction. The mandible then rotated anti-clockwise over the remainder of the 48-week experimental period as a result of anterosuperior displacement of the maxillary complex and dental intrusion (Carlson and Schneiderman, 1983).

One consequence of the bite-opening appliance was the anterior repositioning of the condyle, which was sustained for the duration of the experiment. There were no significant changes in the vertical positioning of the condyle. Anatomically, this positional change resulted in a re-configuration of the components of the mandibular joint when the mandible was occluded against the appliance. Therefore, in the process of being translated anteriorly, the condyle was juxtaposed against the downsloping aspect of the articular eminence, which is inferior to the roof of the fossa. It should be noted that in the macaque, the articular eminence does not protrude inferiorly as much as in man. Its inferior surface gradually slopes down to an apex that is less than $2.0 \mathrm{~mm}$ below the level of the rest of the zygomatic arch. Therefore it 
is not particularly restrictive with regard to anteriorcondylar translation (Carlson et al., 1980). At this new mandibular position, the joint space superior to the condyle was reduced, while the joint space posterior to it was increased in size. It is likely that this altered configuration changed the pattern of mechanical forces passing through the joint.

The amount of condylar growth in the experimental group averaged about $1.5 \mathrm{~mm}$ and was directed postero-superiorly. A small $(0.32 \mathrm{~mm}$; $p<0.06$ ) amount of postero-superior condylar growth occurred in the control monkeys. Thus, condylar growth resulting from experimental repositioning of the mandible may represent elevation of attenuated depository activity already occurring in this part of the condyle in young adults.

The magnitude of condylar adaptation was not significantly dependent upon age in the young adult animals. In contrast, the adaptations within the maxillary complex did vary significantly with age $(p<0.05)$ and were considerably more obvious than mandibular adaptations among the same animals (Carlson and Schneiderman, 1983). Thus, although previous experimental studies indicate that the capacity for an animal to respond to such an alteration of mandibular position by condylar growth diminishes during development (Petrovic et al., 1981; McNamara and Carlson, 1979), condylar adaptations were not as much a function of age differences among the young adult monkeys in this sample as was the adaptive capacity of the sutures of the maxillary complex.

Histological studies provide compelling evidence for the hypothesis that the growth of the mandibular condyle in young animals is affected greatly by condylar function and mandibular position (Petrovic, Stutzmann and Oudet, 1975; Petrovic et al., 1981; Stöckli and Willert, 1971; McNamara, 1972; McNamara and Carlson, 1979). Using rhesus monkeys, McNamara and Carlson (1979) demonstrated increased thickness of the postero-superior region of the pre-chondroblastic-chondroblastic zone of the condylar cartilage and deposition of bone inferior to the condylar cartilage in response to mandibular protrusion in juvenile rhesus monkeys. An increase in the size of the posteriorly-directed trabeculae along the posterior border of the ramus was also observed. As in our study, protrusive function produced no alteration in growth activity at the superior region of the condyle.

Meikle (1970) reported cephalometric and histologic findings on three adult rhesus monkeys treated with class II intermaxillary elastics. Overall changes in mandibular size were not observed but histological adaptations were found in the joint. Meikle was unable to conclude whether there was increased condylar growth. In general, his findings are difficult to interpret due to the small sample size and the experimental design (each animal received a unique treatment with regard to magnitude of class II forces and duration of treatment).

McNamara, Hinton and Hoffman (1982) investigated the adaptive potential of the mandibular joint of adult monkeys treated with protrusive appliances histologically. Although the response of the joint was quite variable, the majority of the 12 experimental animals exhibited some adaptive response. The condylar response in six of the animals was qualitatively similar to that found in growing monkeys subjected to the same treatment (McNamara and Carlson, 1979). However, the response was much less in extent and was not related to the duration of treatment. In addition, three animals exhibited little or no detectable response at the joint and three developed crossbites.

In the present study we found cephalometric evidence indicating that mandibular length increased in response to repositioning of the mandible. We found no evidence of crossbite in any animal. However, an earlier study (Carlson and Schneiderman, 1983) showed that treatment with the bite-opening appliance produced a major antero-superior deflection of the maxilla and intrusion of the mandibular dentition.

While our results amplify the general finding of McNamara et al. (1982) that the adult mandibular joint can adapt to altered function, subtle differences in the results of the two studies require attention. The mandibular position brought about by the biteopening appliance involved anterior translation and rotation of the condyle. As this type of condylar movement occurs within the normal masticatory cycle, it is reasonable to assume that it is within normal physiologic range and therefore unlikely to be traumatic to the tissues of the joint. In contrast, the extreme advancement caused by the protrusive appliance as used by McNamara and co-workers may be out of this range, and potentially traumatic in adults. Thus, the fact that condylar growth in the experimental animals in this study was more uniform and was not associated with pathological response may be a function of the manner in which the condyle was repositioned.

As the growth layers of the condylar cartilage are the principal site of compensatory mandibular growth and mandibular lengthening, these studies provide further evidence that the biomechanical environment of the joint is one factor influencing mandibular growth. The long-term cephalometric data we present here serve logically to connect the alteration of joint function with increases in mandibular size, which could only have come about from the histological changes mentioned above. Nevertheless, it is important to note that the statistical evidence of mandibular lengthening indicates only the presence of an adaptive capability in the condylar cartilage of young adults, not that adaptations are of sufficient magnitude to be of clinical significance.

Acknowledgements - Statistical assistance was provided by Dr Charles Kowalski. This research was supported in part by grants DE 05232 and DE 03610 from the National Institutes of Health.

\section{REFERENCES}

Alt F. B. (1982) Bonferroni inequalities and intervals. In: Encyclopedia of Statistical Sciences, Vol. 1 (Edited by Kotz S. and Johnson N. L.). Wiley, New York.

Björk A. (1968) The use of metallic implants in the study of facial growth in children: Method and application. Am. J. phys. Anthrop. 29, 243-254. 
Carlson D. S., McNamara J. A. and Jaul D. H. (1978) Histological analysis of the growth of the mandibular condyle in the rhesus monkey (Macaca mulatta). Am. J. Anat. 151, 103-118.

Carlson D. S., McNamara J. A. Jr, Graber L. W. and Hoffman D. L. (1980) Experimental studies of growth and adaptation of the TMJ. In: Current Advances in Oral Surgery, Vol. III (Edited by Irby W. B.). Mosby, St Louis.

Carlson D. S., Ellis E. III, Schneiderman E. D. and Ungerleider J. (1982) Experimental models of surgical intervention in the growing face: Cephalometric analysis in facial growth and relapse. In: The Effect of Surgical Intervention on Craniofacial Growth (Edited by McNamara J. A. Jr, Carlson D. S. and Ribbens K. R.) Monograph 12, Craniofacial Growth Series, Center for Human Growth and Development, The University of Michigan, Ann Arbor.

Carlson D. S. and Schneiderman E. D. (1983) Cephalometric analysis of adaptations after lengthening of the masseter muscle in adult rhesus monkeys, Macaca mulatta. Archs oral Biol. 28, 627-637.

Fox D. J. and Guire K. E. (1976) Documentation for MIDAS. Statistical Research Laboratory, The University of Michigan, Ann Arbor.

Gantt D. (1979) Patterns of dental wear and the role of the canine teeth in the Cercopithecinae. Am. J. phys. Anthrop. 51, 353-360.

Hiniker J. J. and Ramfjord S. P. (1966) Anterior displacement of the mandible in adult rhesus monkeys. $J$, prosth. Dent. 6, 503-512.

Hurme V. O. and Van Wagenen G. (1961) Basic data on the emergence of permanent teeth in the rhesus monkey. Proc. Am. phil. Soc. 105, 105-140.

McNamara J. A. Jr (1972) Neuromuscular and Skeletal Adaptations to Altered Orofacial Function, Monograph I, Craniofacial Growth Series, Center for Human Growth and Development, The University of Michigan, Ann Arbor.
McNamara J. A. Jr and Carlson D. S. (1979) Quantitative analysis of temporomandibular joint adaptations to protrusive function. Am. J. Orthod. 76, 593-611.

McNamara J. A. Jr, Hinton R. J. and Hoffman D. L. (1982) Histological analysis of temporomandibular joint adaptation to protrusive function in young adult rhesus monkeys (Macaca mulatta). Am. J. Orthod. 82, 288-298.

McNamara J. A. Jr, Riolo M. L. and Enlow D. H. (1976) Growth of the maxillary complex in the rhesus monkey (Macaca mulatta). Am. J. phys. Anthrop. 44, 15-26.

Meikle M. C. (1970) The effect of class II intermaxillary force on the dentofacial complex in the adult Macaca mulatta monkey. Am. J. Orthod. 58, 323-340.

Neter J. and Wasserman W. (1974) Applied Linear Statistical Models. Richard D. Irwin, Homewood Illinois.

Petrovic A., Stutzmann J. and Gasson N. (1981) The final length of the mandible: Is it genetically determined? In: Craniofacial Biology (Edited by Carlson D. S.) Monograph 10, Craniofacial Growth Series, Center for Human Growth and Development, The University of Michigan, Ann Arbor.

Petrovic A., Stutzmann J. and Oudet C. (1975) Control processes in the postnatal growth of the condylar cartilage. In: Determinants of Mandibular Form and Growth (Edited by McNamara J. A. Jr) Monograph 4, Craniofacial Growth Series, Center for Human Growth and Development, The University of Michigan, Ann Arbor.

Ramfjord S. P. and Enlow D. H. (1971) Anterior displacement of the mandible in adult rhesus monkeys: Long-term observations. J. prosth. Dent. 26, 517-531.

Robinson G. K. (1982) Behrens-Fisher problem. In: Encyclopedia of Statistical Sciences, Vol. 1 (Edited by Kotz S. and Johnson N. L.). Wiley, New York.

Stöckli P. W. and Willert H. G. (1971) Tissue reactions in the temporomandibular joint resulting from anterior displacement of the mandible in the monkey. Am. J. Orthod 60, 142-155. 